\title{
Small Cyclic Diammonium Cation Templated (110)-oriented 2D Halide (X = I, Br, Cl) Perovskites with White-light Emission
}

Xiaotong Li, ${ }^{\dagger}$ Peijun Guo, ${ }^{\ddagger}$ Mikaël Kepenekian, ${ }^{\S}$ Ido Hadar, ${ }^{\dagger}$ Claudine Katan,,${ }^{\S}$ Jacky Even,

Constantinos C. Stoumpos, ${ }^{\nabla}$ Richard D. Schaller, ${ }^{\dagger, \dagger}$ and Mercouri G. Kanatzidis ${ }^{*} \dagger$

†Department of Chemistry, Northwestern University, 2145 Sheridan Road, Evanston, Illinois 60208, United States

$\ddagger$ Center for Nanoscale Materials, Argonne National Laboratory, 9700 South Cass Avenue, Lemont, Illinois 60439, United States

§Univ Rennes, ENSCR, INSA Rennes, CNRS, ISCR (Institut des Sciences Chimiques de Rennes), UMR 6226, Rennes F-35000, France

//Univ Rennes, INSA Rennes, CNRS, Institut FOTON, UMR 6082, Rennes F-35000, France

$\nabla$ Department of Materials Science and Technology, Voutes Campus, University of Crete, Heraklion GR-70013, Greece

\begin{abstract}
Two-dimensional (2D) halide perovskites exhibit excellent potential for optoelectronics because of their outstanding physical properties and structural diversity. White-light emission is one property of 2D perovskites that originates from self-trapped excitons (STE) in the highly distorted structures. The so-called (110)-oriented 2D perovskites are generally distorted and believed to be good candidates for white-light emitting devices. Here, we report (110)-oriented 2D perovskites, $\mathrm{C}_{4} \mathrm{~N}_{2} \mathrm{H}_{12} \mathrm{PbX}_{4}(\mathrm{X}=\mathrm{I}, \mathrm{Br}, \mathrm{Cl})$, templated by the small cyclic diammonium cation, 3aminopyrrolidine (3APr). Structural characterization by single-crystal X-ray diffraction reveals that the distortion of the inorganic part of the structures is influenced by the stereochemical conformation of the cation between the perovskite layers. The experimental bandgaps follow the trend $\mathrm{I}<\mathrm{Br}<\mathrm{Cl}(2.56 \mathrm{eV}, 3.29 \mathrm{eV}, 3.85 \mathrm{eV}$, respectively). DFT calculations reveal a weak but significant electronic band dispersion along the stacking axis, suggesting a non-negligible interlayer electronic coupling caused by the short proximity of adjacent inorganic layers. The high level of distortion results in the emergence of white-light emission, rarely seen in iodide perovskites, as well as the bromide and chloride isostructural analogues, which provides perfect platform to compare the broad emission mechanism for all three halides. The bromide and chloride perovskites show longer lifetimes and higher color rendering index (CRI) (83 and 85), relevant to solid-state lighting. Temperature-dependent PL measurements confirm that the broad emission comes from different STE mechanism for different halides, with the peak broadening persisting even at low temperature for the chloride compound.
\end{abstract}


Keywords: 2D perovskites, photoluminescence, white-light emission, self-trapped excitons

\section{Introduction}

Hybrid halide perovskites are remarkable emerging semiconductors that are being widely studied as light-absorbers for solar cells, ${ }^{1-3}$ lasers, ${ }^{4-6}$ and emitters for light emitting diodes (LEDs) ${ }^{7-9}$ because of their exceptional optical properties and high tunability. ${ }^{10-12}$ After reaching power conversion efficiencies (PCE) of $23 \%$ for solar cells in just a few years, ${ }^{1-3}$ perovskites have achieved new record external quantum efficiencies (EQE) of $20 \%$ for LEDs in just four years. ${ }^{7-8}$ In addition to the three-dimensional (3D) perovskites $\mathrm{AMX}_{3}\left(\mathrm{~A}=\mathrm{Cs}^{+}, \mathrm{CH}_{3} \mathrm{NH}_{3}{ }^{+}\right.$(MA), or $\left.\mathrm{HC}\left(\mathrm{NH}_{2}\right)_{2}{ }^{+}(\mathrm{FA}) ; \mathrm{M}=\mathrm{Ge}^{2+}, \mathrm{Sn}^{2+}, \mathrm{Pb}^{2+} ; \mathrm{X}=\mathrm{Cl}^{-}, \mathrm{Br}^{-}, \mathrm{I}^{-}\right)$, two-dimensional (2D) perovskites have further boosted this field because of their chemically adjustable structures and tunable bandgaps which enable more stable solar cells ${ }^{13-18}$ and new types of LEDs ${ }^{19-21}$. One of the most unanticipated properties of the 2D perovskites is the room temperature emission of white light, which opens the exciting prospect of understanding how white light can be generated and also possibilities of using these materials for solid-state lighting applications. The general concept and appeal lie in utilizing the structural diversity of two-dimensional (2D) perovskites to synthesize single-source whitelight emitters with desirable chromatic coordinates. ${ }^{22-26} 2 \mathrm{D}$ perovskites can be obtained by chemically slicing the 3D perovskite lattice through different planes, giving (100)-, (110)- and (111)-oriented perovskites. ${ }^{27-30}$ Since the report of 2D perovskites as white-light emitters by Karunadasa and coworkers in $2014,{ }^{22-23}$ several other 2D perovskites ${ }^{25-26,31-36}$ and even some lower-dimensional metal halide hybrids ${ }^{37-39}$ have been demonstrated to exhibit white-light emission at room temperature. The broad emission is associated with lattice distortion to generate self-trapped excitons (STE), facilitated by the phonon-assisted emissive relaxation of the strongly bound exciton resulting from quantum confinement. ${ }^{30,40}$ The precise mechanism of action in these materials is still under debate, ${ }^{22-23,31}$ but it is generally accepted that it is strongly correlated to the structural distortion of the perovskite layers in the ground state.

Among the most distorted 2D perovskites are the (110)-oriented members, which are relatively uncommon. ${ }^{27-30}$ This type of structure was first reported by Mitzi and co-workers, who described tin based perovskites templated by the small iodoformamidinium (IFO) cation. ${ }^{41}$ Other examples of (110)-oriented Sn perovskites include $\left(\mathrm{C}\left(\mathrm{NH}_{2}\right)_{3}\right)_{2} \mathrm{SnI}_{4},{ }^{42-43} \alpha-\left(\mathrm{NH}_{3} \mathrm{C}_{5} \mathrm{H}_{10} \mathrm{NH}_{3}\right) \mathrm{SnI}_{4},{ }^{44} \alpha-$ (HA) $\mathrm{SnI}_{4}\left(\mathrm{HA}=\right.$ histammonium). ${ }^{45}$ For the $\mathrm{Pb}$ perovskites, examples include the $(\mathrm{IFO})_{2} \mathrm{PbI}_{4}{ }^{46}$ and $\left(\mathrm{C}\left(\mathrm{NH}_{2}\right)_{3}\right)_{2} \mathrm{PbI}_{4},{ }^{42,47-48}$ which are the analogues of the $\mathrm{Sn}$ compounds, and $(\mathrm{EDBE}) \mathrm{PbX} 4(\mathrm{EDBE}=$ 
2,2'-(ethylenedioxy)bis(ethylammonium), $\mathrm{X}=\mathrm{I}, \mathrm{Br}){ }^{23}\left(\mathrm{MEDA}^{2} \mathrm{PbBr}_{4}\left(\mathrm{MEDA}^{\prime} \mathrm{N}^{1}-\right.\right.$ methylethane-1,2-diammonium), ${ }^{22} \alpha$-(DMEN)PbBr 4 (DMEN = 2-(dimethylamino)ethylamine) ${ }^{25}$ (epz) $\mathrm{PbBr}_{4}$ (epz = 1-ethylpiperazine), ${ }^{37}\left(\mathrm{C}_{6} \mathrm{H}_{13} \mathrm{~N}_{3}\right) \mathrm{PbBr}_{4},{ }^{49} \mathrm{C}_{3} \mathrm{H}_{11} \mathrm{SN}_{3} \mathrm{PbBr}_{4}{ }^{50}$ and $\mathrm{C}_{4} \mathrm{H}_{12} \mathrm{~N}_{2} \mathrm{PbCl}_{4},{ }^{51}$ most of which are bromide perovskites. Another related emerging branch of corrugated perovskites is the so-called (210)-oriented series, $\left[\mathrm{CH}\left(\mathrm{NH}_{2}\right)_{2}\right]\left[\mathrm{C}\left(\mathrm{NH}_{2}\right)_{3}\right] \mathrm{PbI}_{4}{ }^{29}, \quad{ }^{52-53}$ and $\left[\mathrm{CH}\left(\mathrm{NH}_{2}\right)_{2}\right]\left[\mathrm{HSC}\left(\mathrm{NH}_{2}\right)_{2}\right] \mathrm{PbI}_{4}{ }^{52}$, which also create highly distorted structures and exhibit broadband emission. The extensive lattice distortion in (110)-oriented perovskite derives from the need of the organic cations to pack efficiently within the pockets of the inorganic layers (gallery space) and the soft malleable nature of the inorganic halide framework. In practice, the strongest organic-inorganic interactions occur in the bromide perovskites where hydrogen bonding appears to be the major structure-directing force. This is different from iodides, where hydrogen bonding stabilization is weaker, and chlorides, where the inorganic lattice conformation is dominated by strong ionic interactions. Because of this it is rare to find a cation that can template the same (110)oriented isostructural 2D perovskite for all three halides. Therefore, the opportunity is rare to study optical response as a function of changes in the ionicity of the perovskite lattice structure with different halides as well as the dielectric contrast between the inorganic and organic components. 30

In this paper, we report that 3-aminopyrrolidine (3APr) is a cation which permits the formation of (110)-oriented 2D perovskites for all three halides, in the form of (3APr) $\mathrm{PbX} 4(\mathrm{X}=\mathrm{I}, \mathrm{Br}, \mathrm{Cl})$. We find that all three closely related compounds exhibit broadband white-light emission at room temperature. We further investigate the origin of the broad emission, by performing temperaturedependent photoluminescence measurements and find that a different STE mechanism is responsible for the observed broadband emission for each halide.

\section{Experimental Section}

Materials. $\mathrm{PbO}$ (99.9\%), 3-aminopyrrolidine dihydrochloride (98\%), hydroiodic acid (57 wt \% in $\mathrm{H}_{2} \mathrm{O}$, distilled, stabilized, 99.95\%), hydrobromic acid (ACS reagent, 48 wt \% in $\mathrm{H}_{2} \mathrm{O}$ ), hydrochloric acid (ACS reagent, $37 \mathrm{wt} \%$ in $\mathrm{H}_{2} \mathrm{O}$ ) and hypophosphorous acid solution (50 wt \% in $\mathrm{H}_{2} \mathrm{O}$ ) were purchased from Sigma-Aldrich and used as received.

\section{Synthesis}


(3APr)PbI $4 . \mathrm{PbO}(1 \mathrm{mmol}, 223.2 \mathrm{mg})$ powder was dissolved in a mixture of $1 \mathrm{~mL}$ of $\mathrm{HI}$ solution and $0.2 \mathrm{~mL}$ of $\mathrm{H}_{3} \mathrm{PO}_{2}$ solution under heating to boiling and vigorous stirring. 3-aminopyrrolidine dihydrochloride $(0.25 \mathrm{mmol}, 39.75 \mathrm{mg})$ was added to the clear yellow solution with continuous heating and stirring until the precipitate was dissolved again. Then the temperature was lowered to $125^{\circ} \mathrm{C}$ and kept constant until the orange crystals started to form. Further decrease of the temperature to $75^{\circ} \mathrm{C}$ resulted in the precipitation for most of the crystals, after which the hot plate was turned off and the solution was left to cool to room temperature. After $30 \mathrm{~min}$, the product was isolated by suction filtration and dried on the filtration funnel for a further $30 \mathrm{~min}$. Yield 106.0 $\mathrm{mg}, 52.8 \%$ based on the cation. Gradual decrease of the temperature and usage of substoichiometric ratio of the cation were to avoid the precipitation of undesired light-yellow phase. (3APr)PbBr 4 . $\mathrm{PbO}(2 \mathrm{mmol}, 446.4 \mathrm{mg})$ powder was dissolved in a mixture of $2.5 \mathrm{~mL}$ of $\mathrm{HBr}$ solution and $0.5 \mathrm{~mL}$ of $\mathrm{H}_{3} \mathrm{PO}_{2}$ solution under heating to boiling and vigorous stirring. 3aminopyrrolidine dihydrochloride $(0.4 \mathrm{mmol}, 63.6 \mathrm{mg})$ was added to the clear solution with continuous heating and stirring until the precipitate was dissolved again. Then the heat was turned off and thin transparent plate-shaped crystals started to form after slow evaporation of the solvent for several days. Since no second phase was detected for the bromide analogue, there was no need of gradual cooling. The product was isolated by suction filtration and dried on the filtration funnel for a further $30 \mathrm{~min}$. Yield $64.3 \mathrm{mg}, 26.1 \%$ based on the cation. Sub-stoichiometric ratio of the cation and diluted concentration were used to improve the quality of the crystals.

(3APr) $\mathrm{PbCl}_{4}$. $\mathrm{PbO}(0.4 \mathrm{mmol}, 89.3 \mathrm{mg})$ powder was dissolved in a mixture of $2.5 \mathrm{~mL}$ of $\mathrm{HCl}$ solution and $0.5 \mathrm{~mL}$ of $\mathrm{H}_{3} \mathrm{PO}_{2}$ solution under heating to boiling and vigorous stirring. 3aminopyrrolidine dihydrochloride $(1.2 \mathrm{mmol}, 190.8 \mathrm{mg})$ was added to the clear solution with continuous heating and stirring until the precipitate was dissolved again. Then the heat was turned off and thin transparent plate-shaped crystals started to form after slow evaporation of the solvent for several days. Since no second phase was detected for the bromide analogue, there was no need of gradual cooling. The product was isolated by suction filtration and dried on the filtration funnel for a further $30 \mathrm{~min}$. Yield $83.9 \mathrm{mg}, 48.0 \%$ based on total $\mathrm{Pb}$. Extra amount of the cation was added to prevent the formation of $\mathrm{PbCl}_{2}$.

Single-Crystal X-ray Diffraction. The compounds were collected either using a Bruker DUO or Molly instrument with a Mo K $\alpha \mu \mathrm{IS}$ microfocus source $(\lambda=0.71073 \AA)$ with MX Optics at $298 \mathrm{~K}$ for all three compounds and at $250 \mathrm{~K}$ for the bromide compound. The collected data were 
integrated and applied with numerical absorption corrections using the APEX3 software. The structures were solved by charge flipping and refined by full-matrix least-squares on $\mathrm{F}^{2}$ using the Jana 2006 package..$^{54}$ The PLATON ${ }^{55}$ software was used to validate the space groups of the compounds.

Computational Details. First-principles calculations are based on density functional theory (DFT) as implemented in the SIESTA package ${ }^{56-57}$ Calculations have been carried out on experimental structures with the GGA functional in the revPBE form. ${ }^{58}$ Core electrons are described with Troullier-Martins pseudopotentials. ${ }^{59}$ The valence wavefunctions are developed over double- $\zeta$ polarized basis set of finite-range numerical pseudoatomic orbitals. ${ }^{60} \mathrm{In}$ our calculations, spin-orbit coupling is taken into account through the on-site approximation as proposed by FernándezSeivane et al. ${ }^{61}$ In all cases, an energy cutoff of 150 Ry for real-space mesh size has been used. The Brillouin zone of the $\mathrm{I}, \mathrm{Br}$ and $\mathrm{Cl}$ structures are sampled with $3 \times 1 \times 5,5 \times 1 \times 3$ and $5 \times 1 \times 3$ Monkhorst-Pack $k$-grids, respectively.

Steady-State and Time-Resolved Photoluminescence. The samples were excited at $330 \mathrm{~nm}$ with an optical parametric amplifier, which was pumped by a Ti:sapphire amplifier (Spectra-Physics) with $800-\mathrm{nm}$ output at $2 \mathrm{kHz}$ repetition rate. Time-integrated and time-resolved photoluminescence spectra were acquired with a CCD camera and a streak camera (Hamamatsu), respectively. During the photoluminescence measurements, the samples were mounted in a closedcycle vacuum cryostat under a pressure below $10^{-7}$ Torr. A long pass filter of $370 \mathrm{~nm}$ was used before the detection to remove the excitation light. 


\section{Results and Discussion}

Crystal structures. All compounds reported here belong to the (110)-oriented class of perovskites. They can be synthesized by direct combination of $\mathrm{PbO}$ and the cation source (3-aminopyrrolidine dihydrochloride) in the corresponding concentrated hydrohalic acid as a solvent. The ratios of the starting materials and the concentrations were varied because of the different solubilities of the products, with detailed synthesis procedures listed in the experimental section.

The formation of the same type of (110)-oriented structures for all iodide, bromide and chloride perovskites templated by the same cation is rare, because tolerance factors of the inorganic framework to the same cation change for the different $\mathrm{Pb}-\mathrm{X}$ bond lengths. However, when the spacer cation is small, it is possible to satisfy the formability conditions for all three halides. ${ }^{29}$ The $\mathrm{Pb}-\mathrm{I}$ bond length is the longest among $\mathrm{Pb}-\mathrm{X}$ and creates the largest space to accommodate the cation. Besides, the electronegativity of iodine is the smallest among $\mathrm{X}$, so the hydrogen bonding strength of the iodine atoms with the $\mathrm{N}-\mathrm{H}$ is the weakest. Therefore, the cation in the iodide perovskite has the largest "freedom" to choose the most suitable conformation without a significant energetic penalty. In the case of $(3 \mathrm{APr}) \mathrm{PbI}_{4}$, the preferable conformation has the pyrrolidine ring lying perpendicular to the stacking axis (Figure 1). It is worth pointing out that the conformation of the cation is identified directly by the electron density of the carbon and nitrogen atoms and is refined without ambiguity. The iodide compound adopts the $P n a 2_{1}$ space group, with all $-\mathrm{NH}_{2}{ }^{+}$ groups on the pyrrolidine ring pointing in the same direction, resulting in a polar noncentrosymmetric space group. The alternative centrosymmetric space group Pnma was eliminated because the mirror plane results in doubled (disordered) nitrogen atoms in the ring. The bromide and chloride analogues adopt the centric $P 2{ }_{1} / c$ space group, with the ring lying parallel to the stacking axis. The two cations, related by the glide plane, have the pyrrolidine $-\mathrm{NH}_{2}{ }^{+}$groups pointing in opposite directions, resulting in the centrosymmetric space group. We note that the cation is chiral and the reagent we use in the synthesis is a racemic mixture. Because of the existence of the glide planes, cations related by any sort of mirror must be enantiomers. So we can infer that enantiomers are $50 \% \mathrm{R}$ and $50 \% \mathrm{~S}$, which make sense according to the starting materials we used.

The unit-cell dimensions (Table 1) of the bromide and chloride compounds can be estimated by a $\sim 2^{*} \mathrm{x}$ ( $\mathrm{x}$ is the length of $\mathrm{Pb}-\mathrm{X}$ bond), $\mathrm{c} \sim \sqrt{2} * \mathrm{a}$ and the stacking axis $\mathrm{b} \sim 2 * \mathrm{c}+\mathrm{d}$ ( $\mathrm{d}$ is the spacing 
between the inorganic planes). This rough estimation can provide the correct trend, but the values may not be accurate because the $\mathrm{X}-\mathrm{Pb}-\mathrm{X}$ angles are not exactly orthogonal (see below). The a and $c$ axes are switched for the iodide compound, but the trend is similar except that the $b$ axis is shorter due to the different conformation of the cation. The closest interlayer halide-halide distances for I-I, Br-Br and Cl-Cl are 4.1353(30) $\mathrm{A}, 4.3227(23) \AA$ and 4.2202(27) $\AA$, respectively. The close X$\mathrm{X}$ distance may result in some $\mathrm{X}-\mathrm{X}$ interaction and weak electronic coupling between the inorganic layers (more discussion in the section of the electronic structure calculation below). The tightly packed layers lead to distorted $\mathrm{Pb}-\mathrm{X}$ bonds in order to tolerate the large geometric constraints imposed by the large cation. Some $\mathrm{Pb}-\mathrm{X}$ bonds are elongated, with the longest $\mathrm{Pb}-\mathrm{I}, \mathrm{Pb}-\mathrm{Br}$ and $\mathrm{Pb}$ -

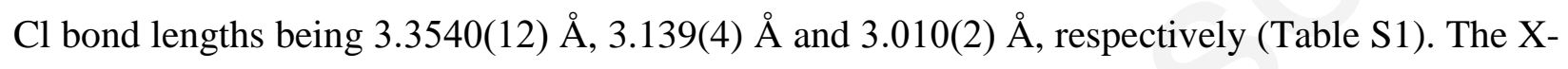
$\mathrm{Pb}-\mathrm{X}$ angles are also expanded, with the largest $\mathrm{X}-\mathrm{Pb}-\mathrm{X}$ angles being close to $100^{\circ}$ for all three compounds (Table S2).

Here in, we calculated the mean distortion level of each octahedron in each compound (Table 2).

The bond length distortion is defined by equation (1), ${ }^{62-63}$ where $\mathrm{d}$ is the average $\mathrm{Pb}-\mathrm{X}$ bond distance and $d_{n}$ are the six individual bond distances. Similarly, the bond angle variance ${ }^{64}$ (equation (2), where $\theta_{\mathrm{i}}$ is the individual $\mathrm{X}-\mathrm{Pb}-\mathrm{X}$ angle) reflect the angle deviation from $90^{\circ}$ of the nondistorted structure.

$$
\begin{aligned}
\Delta d & =\left(\frac{1}{6}\right) \sum\left[\frac{d_{n}-d}{d}\right]^{2} \\
\sigma^{2} & =\sum_{i=1}^{12}\left(\theta_{i}-90\right)^{2} / 11
\end{aligned}
$$

All three compounds exhibit high degree of bond distortion and are more distorted than the more commonly seen (100)-oriented 2D perovskites (Table 2). It has been argued that the broad PL emission is associated with high level of distortion of the structure. ${ }^{25-26}$ In this context, the bond length distortion for the iodide compound is larger than the other two because of the tighter packing of the cation in the perovskite layer pockets, as a result of its distinctive stereochemical conformation. The conformation of the ring lying perpendicular to the stacking axis requires more space in the ac plane than in the cross-plane direction, so the $\mathrm{Pb}$-I bonds along the perovskite plane are the most distorted. In the case of the lower halide analogues the most distorted layer direction is along the stacking axis, owing to the influence of extensive hydrogen bonding that stretches the 
perovskite perpendicular to its natural expansion plane. This trend is more clearly shown as discussed below.

Differential scanning calorimetry (DSC) (Figure S1) on the compounds in the temperature range of $125 \sim 400 \mathrm{~K}$ shows that the bromide compound exhibits a phase transition at $\sim 280 \mathrm{~K}$. The reconstructive character of the phase transition between the high and low temperature distortions of the bromide structure is consistent with the first order heat flow anomaly measured by DSC. Measurement of the crystal structure at $250 \mathrm{~K}$ (Figure S2) shows that the bromide structure at 250 $\mathrm{K}$ is similar to the iodide structure at $298 \mathrm{~K}$, with the ring lying perpendicular to the stacking direction, accompanied by a significant contraction of the b-axis and an expansion along the ac plane (Table S3). Upon the phase transition, the inorganic part becomes more distorted to accommodate the cation, with the $\mathrm{Pb}-\mathrm{Br}$ distance along the a axis elongated to $3.40 \AA$, which is much longer than the $\mathrm{Pb}-\mathrm{Br}$ bond length in the 3D structure $(2.97 \AA)$. The bond length distortion $\Delta \mathrm{d}\left(35.2 \times 10^{-4}\right)$ and the bond angle variance $\sigma^{2}(43.6)$ are also much larger than the values at room temperature, which implies that the structure with perpendicular ring conformation is more distorted than that with the parallel one.

The experimental powder X-ray diffraction (PXRD) patterns at room temperature match very well with the calculated PXRD (Figure S3). At room temperature, the PXRD patterns of the bromide and chloride compounds exhibit similar trends in the low angle ranges, with the bromide peaks shifted to the lower $2 \theta$ (because of larger d-spacing), emphasizing their structural similarity. The first low angle peak in the powder patterns corresponds to the $(0 \mathrm{k} 0)$ planes in the crystal structure, which reflect the length of the $b$ axes in the unit cells. At room temperature, the bromide compound has the longest $b$ axis, followed by the chloride compound and then the iodide one. The difference of the iodide pattern from the other two indicates the pronounced difference between the two structure types.

Electronic structure calculations. We calculated the electronic band structures using DFT for ( $3 \mathrm{APr}) \mathrm{PbX}_{4}(\mathrm{X}=\mathrm{I}, \mathrm{Br}, \mathrm{Cl})$ (Figure 2), using the experimentally determined crystal structures at $298 \mathrm{~K}$. The calculated fundamental bandgaps for $(3 \mathrm{APr}) \mathrm{PbI}_{4},(3 \mathrm{APr}) \mathrm{PbBr}_{4}$ and $(3 \mathrm{APr}) \mathrm{PbCl}_{4}$ are $1.71 \mathrm{eV}, 2.12 \mathrm{eV}$ and $2.58 \mathrm{eV}$, respectively, which follow the experimental trend that $E_{g(\mathrm{I})}<E_{g(\mathrm{Br})}$ $<E_{g(\mathrm{Cl})}$ even though the actual numbers are underestimated by DFT. The valence band maximum (VBM) consists of $\mathrm{Pb}$ s-orbitals and halide p-orbitals while the conduction band minimum (CBM) 
is dominated by empty $\mathrm{Pb}$ p-orbitals (Figure S4-S6). Increasing halide electronegativity from I to $\mathrm{Cl}$ would lower the VBM while keeping the CBM almost unchanged, thus increasing the bandgaps. The band structures for the (110)-oriented 2D perovskites are similar to those of the (100)-oriented ones, but it is worth pointing out that there are low but significant dispersions along the stacking axes, as shown in the zoomed in pictures in Figure S7. The band dispersions are easier to observe for the direct bandgap bromide and chloride compound, but they become more complicated for the iodide compound because of the Rashba splitting effect arising from the simultaneous presence of large spin-orbit coupling and the polarity of the crystal lattice. ${ }^{65}$ Here, the polar axis lies along the c axis (the binary axis of the $P n a 2_{1}$ structure), which is perpendicular to the stacking axis. Therefore, an incomplete Rashba effect is expected with no splitting of the non-dispersive bands marking the stacking. The fact that the splitting can be seen in two directions (Figure S7a) instead of only one direction for the totally flat bands of the most commonly seen (100)-oriented 2D perovskites $^{16,66}$ confirms the existence of dispersion. This comes from electronic coupling of inorganic layers along the stacking axis because of the short halide-halide distances between the inorganic layers. But since the inorganic layers are not stacking exactly on top of each other, the interlayer electronic coupling also may show up in the band dispersion along the other two directions. The band dispersion of this series is not as large as the (100)-oriented 2D perovskites stacking on top of each other such as Dion-Jacobson phase with similar small distances between the inorganic layers. ${ }^{17}$

Optical properties. The absorption spectra of the compounds are shown in Figure 3a and their optical properties are summarized in Table 3 . The absorption spectra are similar to those of the (100)-oriented 2D perovskite, all exhibiting a pronounced exciton peak and an absorption edge. We estimate the bandgap by extrapolating the high-energy absorption edge to imaginary axis parallel to the $\mathrm{x}$ axis where the absorption edge is interrupted by the low energy exciton peak. ${ }^{66-67}$ They exhibit the same trend as the calculated bandgaps that $E_{g(\mathrm{I})}<E_{g(\mathrm{Br})}<E_{g(\mathrm{Cl})}$.

The photoluminescence (PL) spectra of all the compounds exhibit a broadband feature spanning across the entire visible range at room temperature (Figure $3 b$ ). The main emission peaks of the PL spectra are summarized in Table 3, which show significant Stokes shift from their absorption edge for the bromide and chloride compounds. White-light emission is associated with distorted structures to generate self-trapped excitons (STE) (Figure 4a), ${ }^{22-24,31}$ which is more commonly seen in bromide and chloride perovskites ${ }^{22-26}$ and very rare to be found in iodide perovskites. 
However, because the unique size of the cation, the generally distorted (110)-oriented structures can be formed for all three halides. More importantly, it has been shown in the bromide structure that the cation conformation lying perpendicular to the stacking axis needs more space inside the gallery space than the parallel conformation, so the iodide structure is heavily distorted. The unique size and conformation of the cation give rise to the highly distorted structure of the iodide compound and result in the white-light emission at room temperature, more detailed mechanism will be discussed below.

All three compounds exhibit relatively warm white-light emission, with Correlated Color Temperature (CCT) below $4500 \mathrm{~K}$. The chromaticity coordinates and CCT were obtained using the ColorCalculator by OSRAM Sylvania, Inc, as shown in Figure 4b. Their coordinates (Table 3) deviate from the white point $(0.33,0.33)$, because of the weak emission in the blue region and the dominant contribution of the red emission region. The color rendering indexes (CRI) are relatively high for all the compounds (Table 3), which provides high fidelity of the actual color. In general, a source with a CRI above 70 would be considered acceptable for interior applications, whereas that above 80 would be considered good and that above 90 is excellent. ${ }^{68}$ The high CRI values for the bromide and chloride compounds ( 83 and 85 , respectively) show significant potential for further applications.

Mechanism Study by Temperature-dependent PL. To explore the mechanism of the broad emission, we performed variable-temperature PL for all three compounds. The temperaturedependent PL spectra for the iodide compound from $295 \mathrm{~K}$ to $5 \mathrm{~K}$ are shown in Figure 5a. At room temperature, the PL spectrum is broad spanning from $1.73 \mathrm{eV}$ to $2.61 \mathrm{eV}$ (475 nm to $715 \mathrm{~nm}$ ), with the main peak centered at $2.29 \mathrm{eV}(540 \mathrm{~nm})$. At room temperature, the PL lifetime of the whole spectrum range is fitted to a two-exponential decay, $\tau=a_{1} \times e^{\tau_{1}}+a_{2} \times e^{\tau_{2}}+b$, where $\tau$ 1 and $\tau_{2}$ correspond to the lifetimes of the fast and slow decays. The ratio of photons in each decay can be calculated by $P h_{x}=\left(a_{x} \times \tau_{x}\right) /\left(a_{1} \times \tau_{1}+a_{2} \times \tau_{2}\right),(\mathrm{x}=1,2)$. Therefore, the average lifetime can be defined by $\tau_{\text {avg }}=P h_{1} \times \tau_{1}+P h_{2} \times \tau_{2}$, which equals $0.53 \mathrm{~ns}, 1.72 \mathrm{~ns}$ and 1.01 ns for the iodide, bromide and chloride compounds, respectively (Table 3 ) and comparable to the lifetimes of other 2D perovskite of the same halide. ${ }^{23,25-26,37}$

As the temperature decreases, the main peak of the PL spectra of the iodide compound shifts to higher energy, which later evolves into a distinct peak. The lifetime of the peak first increases to $0.96 \mathrm{~ns}$ at $235 \mathrm{~K}$, followed by a decrease to $0.46 \mathrm{~ns}$ at $205 \mathrm{~K}$ as the high energy part starts to 
develop into a separate peak (Figure 5b). Therefore, the PL spectra are cut into two separate parts of high energy free excitons (FE) peak $(2.25 \mathrm{eV}$ to $3.65 \mathrm{eV})$ and low energy self-trapped excitons (STE) peak (1.48 eV to $2.25 \mathrm{eV}$ ) to get better fitting of the PL decay (Figure S8). Then the lifetime of the STE increases again to a maximum of $4.61 \mathrm{~ns}$ at $55 \mathrm{~K}$ as the peak becomes more distinct, while the lifetime of the FE keeps decreasing from $0.88 \mathrm{~ns}$ at $205 \mathrm{~K}$ to $0.31 \mathrm{~ns}$ at $5 \mathrm{~K}$. The selftrapping depth can be estimated by the difference between the energy minimum of the FE and STE, which is $0.53 \mathrm{eV}, 0.81 \mathrm{eV}$ and $1.05 \mathrm{eV}$ for the iodide, bromide and chloride compounds, respectively. This suggests that the iodide compound is the easiest one to trap and detrap (Figure 4a) so that the FE and STE are preserved through the entire explored temperature range. Note it is possible that there are several STE states as shown in Figure 4a.

For the bromide compound, the main peak first shifts to lower energy upon decreasing to $115 \mathrm{~K}$, then shifts back to higher energy and becomes narrower (Figure 5c) with further decrease. The lifetime of the main peak first increases to a maximum of $17.70 \mathrm{~ns}$ at $55 \mathrm{~K}$ (Figure $5 \mathrm{~d}$ ), then starts to decrease as the sharp FE peak at $2.78 \mathrm{eV}(446 \mathrm{~nm})$ appears, which is more obviously seen in Figure S12cd. Like the iodide perovskite, the PL spectra of the bromide compound are cut at 2.48 $\mathrm{eV}$. Even though it is somewhat arbitrary at which temperature the spectrum may be deemed separated, it generally gives better fitting of the PL decay after cutting (Figure S8-10). The lifetime of the FE increases to a maximum of $2.06 \mathrm{~ns}$ at $5 \mathrm{~K}$ while the STE peak gradually decreases in prominence. The STE dominates at high temperature because there is enough thermal energy (higher than $\mathrm{E}_{\text {trap }}$ ) to exceed the barrier from FE to STE. As temperature decreases, the thermal energy is becoming insufficient to overcome the barrier, so the intensity of the FE increases until it dominates at $5 \mathrm{~K}$, when very few excitons can cross the barrier to the STE states.

Unlike the iodide and bromide compounds, the STE emission dominates over the entire probed temperature range for the chloride compound, and a shoulder of high energy FE can be more clearly seen in Figure S13cd. The lifetimes of the chloride compound follow the same trend as the bromide one, where the main peak lifetime first increases to a maximum of $19.59 \mathrm{~ns}$ at $115 \mathrm{~K}$, followed by a decrease as the FE peak shows up. This suggests that the trap-states are deeper for the chloride compounds, possibly because of the larger energy of the associated phonons, and also because it requires higher energy to detrap (Figure 4a), thus justifying the highest energy difference between the FE and STE $(1.05 \mathrm{eV}) .{ }^{34}$ 
Comparing the three compounds, they all have enough thermal energy to cross the barrier at room temperature $\left(\mathrm{k}_{\mathrm{B}} \mathrm{T}>\mathrm{E}_{\text {trap }} ; \mathrm{k}_{\mathrm{B}}=\right.$ Boltzmann constant, $\left.\mathrm{T}=295 \mathrm{~K}\right)$, reaching the STE states (Figure 4a). As temperature decreases, the iodide compound first reaches the limit where the thermal energy becomes insufficient to exceed the barrier, as indicated by the appearance of the FE peak, then follows the bromide compound and then the chloride compound, suggesting that $E_{\text {trap, }}>$ $\mathrm{E}_{\text {trap,Br }}>\mathrm{E}_{\text {trap,Cl. }}$. However, since the chloride compound has the largest self-trapping depth (1.05 $\mathrm{eV}$ ), once the carriers get trapped, it is unlikely for them to detrap back to the FE states, making the STE states dominating even at low temperature. While the self-trapping depth for the bromide compound is moderate and that for the iodide compound is small, limited ratio of carriers may detrap back to the FE states for the iodide perovskite, but it is less probable for the bromide composition.

\section{Conclusions}

We have demonstrated that the small cation (3APr) templates the same (110)-oriented 2D perovskites for all the three halides, ( $3 \mathrm{APr}) \mathrm{PbX}_{4}(\mathrm{X}=\mathrm{I}, \mathrm{Br}, \mathrm{Cl})$. The unique size and shape of the cation gives rise to the highly distorted structures because the flexible conformation of the organic cation which can lie either parallel or perpendicular to the layer stacking axis. This results in the emergence of white-light emission, rarely seen in iodide perovskites, as well as the bromide and chloride isostructural analogues. The bromide and chloride compounds exhibit longer lifetime and higher CRI values than the iodide one. The mechanism as studied by temperature-dependent PL suggests that the broadband emission arises from the STE, where detrapping energy is the highest for the chloride compound where STE dominates even at low temperature. Comparative studies of white-light emission for all three isostructural halide perovskites as a set may advance the understanding of the mechanism for white-light emission in 2D perovskites.

\section{Associated Content}

\section{Supporting Information}

More experimental details for X-ray diffraction, absorption spectroscopy, crystallographic details, thermal analysis (DSC), additional calculation data and PL data.

X-ray crystallographic data for (3APr)PbI 4 . 
X-ray crystallographic data for $(3 \mathrm{APr}) \mathrm{PbBr}_{4}$.

$\mathrm{X}$-ray crystallographic data for $(3 \mathrm{APr}) \mathrm{PbCl}_{4}$.

Author information

\section{Corresponding Author}

*m-kanatzidis@northwestern.edu.

\section{Notes}

The authors declare no competing financial interest.

\section{Acknowledgements}

This work was supported by the Office of Naval Research, under Grant N00014-17-1-2231 (synthesis, structural characterization of materials, stability studies M.G.K.). This work was performed, in part, at the Center for Nanoscale Materials, a U.S. Department of Energy Office of Science User Facility, and supported by the U.S. Department of Energy, Office of Science, under Contract No. DE-AC02-06CH11357. DFT calculations were performed at the Institut des Sciences Chimiques de Rennes, which received funding from the Agence Nationale pour la Recherche (TRANSHYPERO project) and the work was granted access to the HPC resources of TGCC/CINES/IDRIS under the allocation 2018-A0010907682 made by GENCI. M. K. acknowledges support from Region Bretagne through Boost'ERC LaHPerOS project. J.E acknowledges the financial support from the Institut Universitaire de France. This work made use of the IMSERC at Northwestern University, which has received support from the Soft and Hybrid Nanotechnology Experimental (SHyNE) Resource (NSF ECCS-1542205), the State of Illinois, and the International Institute for Nanotechnology (IIN). Use of the Center for Nanoscale Materials, an Office of Science user facility, was supported by the U.S. Department of Energy, Office of Science, Office of Basic Energy Sciences, under Contract No. DE-AC02-06CH11357. 


\section{References}

1. $\quad$ Arora, N.; Dar, M. I.; Hinderhofer, A.; Pellet, N.; Schreiber, F.; Zakeeruddin, S. M.; Grätzel, M., Perovskite solar cells with CuSCN hole extraction layers yield stabilized efficiencies greater than $20 \%$. Science 2017, 358 (6364), 768-771.

2. $\quad$ Tsai, H.; Asadpour, R.; Blancon, J.-C.; Stoumpos, C. C.; Durand, O.; Strzalka, J. W.; Chen, B.; Verduzco, R.; Ajayan, P. M.; Tretiak, S.; Even, J.; Alam, M. A.; Kanatzidis, M. G.; Nie, W.; Mohite, A. D., Light-induced lattice expansion leads to high-efficiency perovskite solar cells. Science 2018, 360 (6384), 67-70.

3. Y Yang, W. S.; Park, B.-W.; Jung, E. H.; Jeon, N. J.; Kim, Y. C.; Lee, D. U.; Shin, S. S.; Seo, J.; Kim, E. K.; Noh, J. H.; Seok, S. I., Iodide management in formamidinium-lead-halide-based perovskite layers for efficient solar cells. Science 2017, 356 (6345), 1376-1379.

4. $\quad$ Fu, Y.; Zhu, H.; Stoumpos, C. C.; Ding, Q.; Wang, J.; Kanatzidis, M. G.; Zhu, X.; Jin, S., Broad Wavelength Tunable Robust Lasing from Single-Crystal Nanowires of Cesium Lead Halide Perovskites $\left(\mathrm{CsPbX}_{3}, \mathrm{X}=\mathrm{Cl}, \mathrm{Br}, \mathrm{I}\right)$. ACS Nano 2016, 10 (8), 7963-7972.

5. $\quad$ Zhu, H.; Fu, Y.; Meng, F.; Wu, X.; Gong, Z.; Ding, Q.; Gustafsson, M. V.; Trinh, M. T.; Jin, S.; Zhu, X. Y., Lead halide perovskite nanowire lasers with low lasing thresholds and high quality factors. Nat. Mater. 2015, 14, 636.

6. $\quad$ Eaton, S. W.; Lai, M.; Gibson, N. A.; Wong, A. B.; Dou, L.; Ma, J.; Wang, L.-W.; Leone, S. R.; Yang, P., Lasing in robust cesium lead halide perovskite nanowires. Proc. Natl. Acad. Sci. 2016, 113 (8), 1993-1998.

7. Cao, Y.; Wang, N.; Tian, H.; Guo, J.; Wei, Y.; Chen, H.; Miao, Y.; Zou, W.; Pan, K.; He, Y.; Cao, H.; Ke, Y.; Xu, M.; Wang, Y.; Yang, M.; Du, K.; Fu, Z.; Kong, D.; Dai, D.; Jin, Y.; Li, G.; Li, H.; Peng, Q.; Wang, J.; Huang, W., Perovskite light-emitting diodes based on spontaneously formed submicrometrescale structures. Nature 2018, 562 (7726), 249-253.

8. $\quad$ Lin, K.; Xing, J.; Quan, L. N.; de Arquer, F. P. G.; Gong, X.; Lu, J.; Xie, L.; Zhao, W.; Zhang, D.; Yan, C.; Li, W.; Liu, X.; Lu, Y.; Kirman, J.; Sargent, E. H.; Xiong, Q.; Wei, Z., Perovskite light-emitting diodes with external quantum efficiency exceeding 20 percent. Nature 2018, 562 (7726), 245-248.

9. Luo, J.; Wang, X.; Li, S.; Liu, J.; Guo, Y.; Niu, G.; Yao, L.; Fu, Y.; Gao, L.; Dong, Q.; Zhao, C.; Leng, M.; Ma, F.; Liang, W.; Wang, L.; Jin, S.; Han, J.; Zhang, L.; Etheridge, J.; Wang, J.; Yan, Y.; Sargent, E. H.; Tang, J., Efficient and stable emission of warm-white light from lead-free halide double perovskites. Nature 2018, 563 (7732), 541-545.

10. Stoumpos, C. C.; Kanatzidis, M. G., The Renaissance of Halide Perovskites and Their Evolution as Emerging Semiconductors. Acc. Chem. Res. 2015, 48 (10), 2791-2802.

11. Stoumpos, C. C.; Kanatzidis, M. G., Halide Perovskites: Poor Man's High-Performance Semiconductors. Adv. Mater. 2016, 28 (28), 5778-5793.

12. Wang, N.; Liu, W.; Zhang, Q., Perovskite-Based Nanocrystals: Synthesis and Applications beyond Solar Cells. Small Meth. 2018, 2 (6), 1700380.

13. Smith, I. C.; Hoke, E. T.; Solis-Ibarra, D.; McGehee, M. D.; Karunadasa, H. I., A Layered Hybrid Perovskite Solar-Cell Absorber with Enhanced Moisture Stability. Angew. Chem., Int. Ed. 2014, 53 (42), 11232-11235.

14. Cao, D. H.; Stoumpos, C. C.; Farha, O. K.; Hupp, J. T.; Kanatzidis, M. G., 2D Homologous Perovskites as Light-Absorbing Materials for Solar Cell Applications. J. Am. Chem. Soc. 2015, 137 (24), 7843-7850.

15. Tsai, H.; Nie, W.; Blancon, J.-C.; Stoumpos, C. C.; Asadpour, R.; Harutyunyan, B.; Neukirch, A. J.; Verduzco, R.; Crochet, J. J.; Tretiak, S.; Pedesseau, L.; Even, J.; Alam, M. A.; Gupta, G.; Lou, J.; Ajayan, P. M.; Bedzyk, M. J.; Kanatzidis, M. G.; Mohite, A. D., High-efficiency two-dimensional RuddlesdenPopper perovskite solar cells. Nature 2016, 536 (7616), 312-316.

16. Li, X.; Hoffman, J.; Ke, W.; Chen, M.; Tsai, H.; Nie, W.; Mohite, A. D.; Kepenekian, M.; Katan, C.; Even, J.; Wasielewski, M. R.; Stoumpos, C. C.; Kanatzidis, M. G., Two-Dimensional Halide Perovskites 
Incorporating Straight Chain Symmetric Diammonium Ions, $\left(\mathrm{NH}_{3} \mathrm{C}_{\mathrm{m}} \mathrm{H}_{2 \mathrm{~m}} \mathrm{NH}_{3}\right)\left(\mathrm{CH}_{3} \mathrm{NH}_{3}\right)_{\mathrm{n}-1} \mathrm{~Pb}_{\mathrm{n}} \mathrm{I}_{3 \mathrm{n}+1}(\mathrm{~m}=4-$ 9; $\mathrm{n}=1-4) . J$. Am. Chem. Soc. 2018, 140 (38), 12226-12238.

17. Mao, L.; Ke, W.; Pedesseau, L.; Wu, Y.; Katan, C.; Even, J.; Wasielewski, M. R.; Stoumpos, C. C.; Kanatzidis, M. G., Hybrid Dion-Jacobson 2D Lead Iodide Perovskites. J. Am. Chem. Soc. 2018, 140 (10), 3775-3783.

18. Ke, W.; Mao, L.; Stoumpos, C. C.; Hoffman, J.; Spanopoulos, I.; Mohite, A. D.; Kanatzidis, M. G., Compositional and Solvent Engineering in Dion-Jacobson 2D Perovskites Boosts Solar Cell Efficiency and Stability. Adv. Energy Mater. 2019, 9, 1803384.

19. Yuan, M.; Quan, L. N.; Comin, R.; Walters, G.; Sabatini, R.; Voznyy, O.; Hoogland, S.; Zhao, Y.; Beauregard, E. M.; Kanjanaboos, P.; Lu, Z.; Kim, D. H.; Sargent, E. H., Perovskite energy funnels for efficient light-emitting diodes. Nat. Nanotechnol. 2016, 11 (10), 872-877.

20. Yang, X.; Zhang, X.; Deng, J.; Chu, Z.; Jiang, Q.; Meng, J.; Wang, P.; Zhang, L.; Yin, Z.; You, J., Efficient green light-emitting diodes based on quasi-two-dimensional composition and phase engineered perovskite with surface passivation. Nat. Commun. 2018, 9 (1), 570.

21. Wang, N.; Cheng, L.; Ge, R.; Zhang, S.; Miao, Y.; Zou, W.; Yi, C.; Sun, Y.; Cao, Y.; Yang, R.; Wei, Y.; Guo, Q.; Ke, Y.; Yu, M.; Jin, Y.; Liu, Y.; Ding, Q.; Di, D.; Yang, L.; Xing, G.; Tian, H.; Jin, C.; Gao, F.; Friend, R. H.; Wang, J.; Huang, W., Perovskite light-emitting diodes based on solution-processed self-organized multiple quantum wells. Nat. Photonics 2016, 10, 699.

22. Dohner, E. R.; Hoke, E. T.; Karunadasa, H. I., Self-Assembly of Broadband White-Light Emitters. J. Am. Chem. Soc. 2014, 136 (5), 1718-1721.

23. Dohner, E. R.; Jaffe, A.; Bradshaw, L. R.; Karunadasa, H. I., Intrinsic White-Light Emission from Layered Hybrid Perovskites. J. Am. Chem. Soc. 2014, 136 (38), 13154-13157.

24. Smith, M. D.; Karunadasa, H. I., White-Light Emission from Layered Halide Perovskites. Acc. Chem. Res. 2018, 51 (3), 619-627.

25. Mao, L.; Wu, Y.; Stoumpos, C. C.; Wasielewski, M. R.; Kanatzidis, M. G., White-Light Emission and Structural Distortion in New Corrugated Two-Dimensional Lead Bromide Perovskites. J. Am. Chem. Soc. 2017, 139 (14), 5210-5215.

26. Mao, L.; Wu, Y.; Stoumpos, C. C.; Traore, B.; Katan, C.; Even, J.; Wasielewski, M. R.; Kanatzidis, M. G., Tunable White-Light Emission in Single-Cation-Templated Three-Layered 2D Perovskites $\left(\mathrm{CH}_{3} \mathrm{CH}_{2} \mathrm{NH}_{3}\right)_{4} \mathrm{~Pb}_{3} \mathrm{Br}_{10-x} \mathrm{Cl}_{x}$. J. Am. Chem. Soc. 2017, 139 (34), 11956-11963.

27. Saparov, B.; Mitzi, D. B., Organic-Inorganic Perovskites: Structural Versatility for Functional Materials Design. Chem. Rev. 2016, 116 (7), 4558-4596.

28. Smith, M. D.; Crace, E. J.; Jaffe, A.; Karunadasa, H. I., The Diversity of Layered Halide Perovskites. Ann. Rev. Mater. Res. 2018, 48 (1), 111-136.

29. Mao, L.; Stoumpos, C. C.; Kanatzidis, M. G., Two-Dimensional Hybrid Halide Perovskites: Principles and Promises. J. Am. Chem. Soc. 2019, 141 (3), 1171-1190.

30. Katan, C.; Mercier, N.; Even, J., Quantum and Dielectric Confinement Effects in LowerDimensional Hybrid Perovskite Semiconductors. Chem. Rev. 2019, 119 (5), 3140-3192.

31. Smith, M. D.; Jaffe, A.; Dohner, E. R.; Lindenberg, A. M.; Karunadasa, H. I., Structural origins of broadband emission from layered Pb-Br hybrid perovskites. Chem. Sci. 2017, 8 (6), 4497-4504.

32. Thirumal, K.; Chong, W. K.; Xie, W.; Ganguly, R.; Muduli, S. K.; Sherburne, M.; Asta, M.; Mhaisalkar, S.; Sum, T. C.; Soo, H. S.; Mathews, N., Morphology-Independent Stable White-Light Emission from Self-Assembled Two-Dimensional Perovskites Driven by Strong Exciton-Phonon Coupling to the Organic Framework. Chem. Mater. 2017, 29 (9), 3947-3953.

33. Neogi, I.; Bruno, A.; Bahulayan, D.; Goh Teck, W.; Ghosh, B.; Ganguly, R.; Cortecchia, D.; Sum Tze, C.; Soci, C.; Mathews, N.; Mhaisalkar Subodh, G., Broadband-Emitting 2 D Hybrid OrganicInorganic Perovskite Based on Cyclohexane-bis(methylamonium) Cation. ChemSusChem 2017, 10 (19), 3765-3772.

34. Yangui, A.; Garrot, D.; Lauret, J. S.; Lusson, A.; Bouchez, G.; Deleporte, E.; Pillet, S.; Bendeif, E. E.; Castro, M.; Triki, S.; Abid, Y.; Boukheddaden, K., Optical Investigation of Broadband White-Light 
Emission in Self-Assembled Organic-Inorganic Perovskite $\left(\mathrm{C}_{6} \mathrm{H}_{11} \mathrm{NH}_{3}\right)_{2} \mathrm{PbBr}_{4}$. J. Phy. Chem. C 2015, 119 (41), 23638-23647.

35. Li, X.; Do, T. T. H.; Granados del Águila, A.; Huang, Y.; Chen, W.; Xiong, Q.; Zhang, Q., A 3D Haloplumbate Framework Constructed From Unprecedented Lindqvist-like Highly Coordinated $\left[\mathrm{Pb}_{6} \mathrm{Br}_{25}\right]_{13}-$ Nanoclusters with Temperature-Dependent Emission. Chem. Asian. J. 2018, 13 (21), 31853189.

36. Li, X.; Ha Do, T. T.; Granados del Águila, A.; Huang, Y.; Chen, W.; Li, Y.; Ganguly, R.; Morris, S.; Xiong, Q.; Li, D.-s.; Zhang, Q., Two-Dimensional and Emission-Tunable: An Unusual Perovskite Constructed from Lindqvist-Type $\left[\mathrm{Pb}_{6} \mathrm{Br}_{19}\right]_{7}-$ Nanoclusters. Inorg. Chem. 2018, 57 (22), 14035-14038.

37. Mao, L.; Guo, P.; Kepenekian, M.; Hadar, I.; Katan, C.; Even, J.; Schaller, R. D.; Stoumpos, C. C.; Kanatzidis, M. G., Structural Diversity in White-Light-Emitting Hybrid Lead Bromide Perovskites. J. Am. Chem. Soc. 2018, 140 (40), 13078-13088.

38. Yuan, Z.; Zhou, C.; Tian, Y.; Shu, Y.; Messier, J.; Wang, J. C.; van de Burgt, L. J.; Kountouriotis, K.; Xin, Y.; Holt, E.; Schanze, K.; Clark, R.; Siegrist, T.; Ma, B., One-dimensional organic lead halide perovskites with efficient bluish white-light emission. Nat. Commun. 2017, 8, 14051.

39. Lin, H.; Zhou, C.; Tian, Y.; Siegrist, T.; Ma, B., Low-Dimensional Organometal Halide Perovskites. ACS Energy Lett. 2018, 3 (1), 54-62.

40. Guo, P.; Huang, W.; Stoumpos, C. C.; Mao, L.; Gong, J.; Zeng, L.; Diroll, B. T.; Xia, Y.; Ma, X.; Gosztola, D. J.; Xu, T.; Ketterson, J. B.; Bedzyk, M. J.; Facchetti, A.; Marks, T. J.; Kanatzidis, M. G.; Schaller, R. D., Hyperbolic Dispersion Arising from Anisotropic Excitons in Two-Dimensional Perovskites. Phys. Rev. Lett. 2018, 121 (12), 127401.

41. Mitzi, D. B.; Wang, S.; Feild, C. A.; Chess, C. A.; Guloy, A. M., Conducting Layered Organicinorganic Halides Containing <110>-Oriented Perovskite Sheets. Science 1995, 267 (5203), 1473-1476.

42. Daub, M.; Haber, C.; Hillebrecht, H., Synthesis, Crystal Structures, Optical Properties, and Phase Transitions of the Layered Guanidinium-Based Hybrid Perovskites $\left[\mathrm{C}\left(\mathrm{NH}_{2}\right)_{3}\right]_{2} \mathrm{MI}_{4} ; \mathrm{M}=\mathrm{Sn}, \mathrm{Pb}$. Eur. J. Inorg. Chem. 2016, 2017 (7), 1120-1126.

43. Stoumpos, C. C.; Mao, L.; Malliakas, C. D.; Kanatzidis, M. G., Structure-Band Gap Relationships in Hexagonal Polytypes and Low-Dimensional Structures of Hybrid Tin Iodide Perovskites. Inorg. Chem. 2017, $56(1), 56-73$.

44. Guan, J.; Tang, Z; M. Guloy, A., $\alpha-\left[\mathrm{NH}_{3}\left(\mathrm{CH}_{2}\right)_{5} \mathrm{NH}_{3}\right] \mathrm{SnI}_{4}$ : a new layered perovskite structure. Chem. Commun. 1999, (18), 1833-1834.

45. Mao, L.; Tsai, H.; Nie, W.; Ma, L.; Im, J.; Stoumpos, C. C.; Malliakas, C. D.; Hao, F.; Wasielewski, M. R.; Mohite, A. D.; Kanatzidis, M. G., Role of Organic Counterion in Lead- and Tin-Based TwoDimensional Semiconducting Iodide Perovskites and Application in Planar Solar Cells. Chem. Mater. 2016, $28(21), 7781-7792$.

46. Wang, Q.; Jiang, C.; Zhang, P.; Hamann, T. W., Overcoming Bulk Recombination Limits of Layered Perovskite Solar Cells with Mesoporous Substrates. J. Phy. Chem. C 2018, 122 (25), 14177-14185.

47. Szafrański, M., Investigation of phase instabilities in guanidinium halogenoplumbates(II). Thermochimica Acta 1997, 307 (2), 177-183.

48. Szafrański, M.; Katrusiak, A., Phase transitions in the layered structure of diguanidinium tetraiodoplumbate. Phys. Rev. B 2000, 61 (2), 1026-1035.

49. Li, Y. Y.; Lin, C. K.; Zheng, G. L.; Cheng, Z. Y.; You, H.; Wang, W. D.; Lin, J., Novel 〈110〉Oriented Organic-Inorganic Perovskite Compound Stabilized by N-(3-Aminopropyl)imidazole with Improved Optical Properties. Chem. Mater. 2006, 18 (15), 3463-3469.

50. Li, Y.; Zheng, G.; Lin, J., Synthesis, Structure, and Optical Properties of a Contorted $\langle 110\rangle$ Oriented Layered Hybrid Perovskite: $\mathrm{C}_{3} \mathrm{H}_{11} \mathrm{SN}_{3} \mathrm{PbBr}_{4}$. Eur. J. Inorg. Chem. 2008, 2008 (10), 1689-1692.

51. Bonamartini Corradi, A.; Ferrari, A. M.; Righi, L.; Sgarabotto, P., An Additional Structural and Electrical Study of Polymeric Haloplumbates(II) with Heterocyclic Diprotonated Amines. Inorg. Chem. 2001, 40 (2), 218-223. 
52. Daub, M.; Hillebrecht, H., First representatives of (210)-oriented perovskite variants-Synthesis, crystal structures and properties of the new $2 \mathrm{D}$ hybrid perovskites $\mathrm{A}\left[\mathrm{HC}\left(\mathrm{NH}_{2}\right)_{2}\right] \mathrm{PbI}_{4} ; \mathrm{A}=\left[\mathrm{C}\left(\mathrm{NH}_{2}\right)_{3}\right]$, [HSC $\left.\left(\mathrm{NH}_{2}\right)_{2}\right]$. Z. Kristallogr. - Cryst. Mater. 2018, 233 (8), 555.

53. Nazarenko, O.; Kotyrba, M. R.; Yakunin, S.; Aebli, M.; Rainò, G.; Benin, B. M.; Wörle, M.; Kovalenko, M. V., Guanidinium-Formamidinium Lead Iodide: A Layered Perovskite-Related Compound with Red Luminescence at Room Temperature. J. Am. Chem. Soc. 2018, 140 (11), 3850-3853.

54. Petř́iček, V.; Dušek, M.; Palatinus, L., Crystallographic Computing System JANA2006: General features. Z. Kristallogr. - Cryst. Mater. 2014, 229 (5), 345.

55. Spek, A., Structure validation in chemical crystallography. Acta Crystallogr. D 2009, 65 (2), 148155.

56. Artacho, E.; Anglada, E.; Diéguez, O.; Gale, J. D.; García, A.; Junquera, J.; Martin, R. M.; Ordejón, P.; Pruneda, J. M.; Sánchez-Portal, D.; Soler, J. M., The SIESTA method; developments and applicability. J. Phys.: Condens. Matter 2008, 20 (6), 064208.

57. Soler, J. M.; Artacho, E.; Gale, J. D.; García, A.; Junquera, J.; Ordejón, P.; Sánchez-Portal, D., The SIESTA method for ab initio order- N materials simulation. J. Phys.: Condens. Matter 2002, 14 (11), 2745. 58. Zhang, Y.; Yang, W., Comment on "Generalized Gradient Approximation Made Simple". Phys. Rev. Lett. 1998, 80 (4), 890-890.

59. Troullier, N.; Martins, J. L., Efficient pseudopotentials for plane-wave calculations. Phys. Rev. B 1991, 43 (3), 1993-2006.

60. Artacho, E.; Sánchez-Portal, D.; Ordejón, P.; García, A.; Soler, J. M., Linear-Scaling ab-initio Calculations for Large and Complex Systems. Phys. Status Solidi B 1999, 215 (1), 809-817.

61. Fernández-Seivane, L.; Oliveira, M. A.; Sanvito, S.; Ferrer, J., On-site approximation for spinorbit coupling in linear combination of atomic orbitals density functional methods. J. Phys.: Condens. Matter 2006, 18 (34), 7999.

62. Lufaso, M. W.; Woodward, P. M., Jahn-Teller distortions, cation ordering and octahedral tilting in perovskites. Acta Crystallogr. B 2004, 60 (1), 10-20.

63. Alonso, J. A.; Martínez-Lope, M. J.; Casais, M. T.; Fernández-Díaz, M. T., Evolution of the Jahn-Teller Distortion of MnO6 Octahedra in RMnO3 Perovskites (R = Pr, Nd, Dy, Tb, Ho, Er, Y): A Neutron Diffraction Study. Inorg. Chem. 2000, 39 (5), 917-923.

64. Robinson, K.; Gibbs, G. V.; Ribbe, P. H., Quadratic Elongation: A Quantitative Measure of Distortion in Coordination Polyhedra. Science 1971, 172 (3983), 567-570.

65. Pedesseau, L.; Sapori, D.; Traore, B.; Robles, R.; Fang, H.-H.; Loi, M. A.; Tsai, H.; Nie, W.; Blancon, J.-C.; Neukirch, A.; Tretiak, S.; Mohite, A. D.; Katan, C.; Even, J.; Kepenekian, M., Advances and Promises of Layered Halide Hybrid Perovskite Semiconductors. ACS Nano 2016, 10 (11), 9776-9786. 66. Stoumpos, C. C.; Cao, D. H.; Clark, D. J.; Young, J.; Rondinelli, J. M.; Jang, J. I.; Hupp, J. T.; Kanatzidis, M. G., Ruddlesden-Popper Hybrid Lead Iodide Perovskite 2D Homologous Semiconductors. Chem. Mater. 2016, 28 (8), 2852-2867.

67. Saouma, F. O.; Stoumpos, C. C.; Wong, J.; Kanatzidis, M. G.; Jang, J. I., Selective enhancement of optical nonlinearity in two-dimensional organic-inorganic lead iodide perovskites. Nat. Commun. 2017, $8(1), 742$.

68. Ye, S.; Xiao, F.; Pan, Y. X.; Ma, Y. Y.; Zhang, Q. Y., Phosphors in phosphor-converted white light-emitting diodes: Recent advances in materials, techniques and properties. Mater. Sci. Eng., R 2010, $71(1), 1-34$. 
Table 1. Crystal and Refinement Data for $(3 \mathrm{APr}) \mathrm{PbX}_{4}(\mathrm{X}=\mathrm{I}, \mathrm{Br}, \mathrm{Cl})^{\#}$

\begin{tabular}{|c|c|c|c|}
\hline Compound & $(3 \mathrm{APr}) \mathrm{PbI}_{4}$ & $(3 \mathrm{APr}) \mathrm{PbBr}_{4}$ & $(3 \mathrm{APr}) \mathrm{PbCl}_{4}$ \\
\hline Temperature & $298 \mathrm{~K}$ & $298 \mathrm{~K}$ & $298 \mathrm{~K}$ \\
\hline Crystal system & orthorhombic & monoclinic & monoclinic \\
\hline Space group & $P_{n a 2}$ & $P 2{ }_{1} / c$ & $P 2{ }_{1} / c$ \\
\hline Unit cell dimensions & $\begin{array}{l}\mathrm{a}=10.057(2) \AA \\
\mathrm{b}=21.376(3) \AA \\
\mathrm{c}=6.580(7) \AA\end{array}$ & $\begin{array}{l}\mathrm{a}=6.242(4) \AA \\
\mathrm{b}=22.545(13) \AA \\
\mathrm{c}=9.236(5) \AA \\
\beta=94.648(13)^{\circ}\end{array}$ & $\begin{array}{l}\mathrm{a}=5.8860(2) \AA \\
\mathrm{b}=21.7573(7) \AA \\
\mathrm{c}=8.9772(3) \AA \\
\beta=94.922(2)^{\circ}\end{array}$ \\
\hline Volume & $1414.5(16) \AA^{3}$ & $1295.5(13) \AA^{3}$ & $1145.41(7) \AA^{3}$ \\
\hline $\mathrm{Z}$ & 4 & 4 & 4 \\
\hline Density (calculated) & $3.7705 \mathrm{~g} / \mathrm{cm}^{3}$ & $3.1529 \mathrm{~g} / \mathrm{cm}^{3}$ & $2.535 \mathrm{~g} / \mathrm{cm}^{3}$ \\
\hline Index ranges & $\begin{array}{l}-14<=\mathrm{h}<=14 \\
-30<=\mathrm{k}<=30 \\
-3<=\mathrm{l}<=9\end{array}$ & $\begin{array}{l}-8<=\mathrm{h}<=8 \\
-34<=\mathrm{k}<=34 \\
-12<=\mathrm{l}<=13\end{array}$ & $\begin{array}{l}-8<=\mathrm{h}<=8 \\
-30<=\mathrm{k}<=30 \\
-12<=\mathrm{l}<=12\end{array}$ \\
\hline $\begin{array}{l}\text { Independent } \\
\text { reflections }\end{array}$ & $1967\left[\mathrm{R}_{\mathrm{int}}=0.057\right]$ & $2324\left[\mathrm{R}_{\mathrm{int}}=0.0848\right]$ & $2064\left[\mathrm{R}_{\mathrm{int}}=0.0408\right]$ \\
\hline Completeness to $25^{\circ}$ & $100 \%$ & $98 \%$ & $100 \%$ \\
\hline $\begin{array}{l}\text { Data / restraints / } \\
\text { parameters }\end{array}$ & 1967 / 6 / 65 & $2324 / 6 / 65$ & 2064 / 6 / 65 \\
\hline Goodness-of-fit & 1.36 & 1.91 & 2.47 \\
\hline $\begin{array}{l}\text { Final R indices } \\
{[\mathrm{I}>2 \sigma(\mathrm{I})]}\end{array}$ & $\begin{array}{l}\mathrm{R}_{\text {obs }}=0.0304 \\
\mathrm{wR}_{\text {obs }}=0.0402\end{array}$ & $\begin{array}{l}\mathrm{R}_{\mathrm{obs}}=0.0402 \\
\mathrm{wR}_{\mathrm{obs}}=0.0885\end{array}$ & $\begin{array}{l}\mathrm{R}_{\text {obs }}=0.0397 \\
\mathrm{wR}_{\text {obs }}=0.1018\end{array}$ \\
\hline $\mathrm{R}$ indices [all data] & $\begin{array}{l}\mathrm{R}_{\mathrm{all}}=0.0377 \\
\mathrm{wR}_{\mathrm{all}}=0.0410\end{array}$ & $\begin{array}{l}\mathrm{R}_{\mathrm{all}}=0.0598 \\
\mathrm{wR}_{\mathrm{all}}=0.0898\end{array}$ & $\begin{array}{l}\mathrm{R}_{\mathrm{all}}=0.0421 \\
\mathrm{wR}_{\mathrm{all}}=0.1023\end{array}$ \\
\hline $\begin{array}{l}\text { Largest diff. peak } \\
\text { and hole }\end{array}$ & 0.91 and $-0.67 \mathrm{e} \cdot \AA^{-3}$ & 1.30 and $-1.08 \mathrm{e} \cdot \AA^{-3}$ & 1.61 and $-2.14 \mathrm{e} \cdot \AA^{-3}$ \\
\hline
\end{tabular}


Table 2. Summary of Bond Length Distortions $\left(\Delta \mathrm{d}\left(\times 10^{-4}\right)\right)$ and Bond Angle Variance $\left(\sigma^{2}\right)$ for Compounds Reported Here and in Literature

\begin{tabular}{lccc}
\hline & Structure Type & $\Delta \mathrm{d}\left(\times 10^{-4}\right)$ & $\sigma^{2}$ \\
\hline$(3 \mathrm{APr}) \mathrm{PbI}_{4}$ & $" 2 \times 2 "(110)$ & 11.9 & 21.8 \\
$(3 \mathrm{APr}) \mathrm{PbBr}_{4}$ & $" 2 \times 2 "(110)$ & 9.86 & 21.1 \\
$(3 \mathrm{APr}) \mathrm{PbCl}_{4}$ & $" 2 \times 2 "(110)$ & 10.4 & 30.5 \\
$(\mathrm{EDBE}) \mathrm{PbI}_{4}{ }^{23}$ & $" 2 \times 2 "(110)$ & 10.4 & 14.3 \\
$(\mathrm{EDBE}) \mathrm{PbBr}_{4}{ }^{23}$ & $" 2 \times 2 "(110)$ & 13.7 & 23.9 \\
$(\mathrm{MEDA}) \mathrm{PbBr}_{4}{ }^{22}$ & $" 2 \times 2 "(110)$ & 10.8 & 24.5 \\
$\alpha-(\mathrm{DMEN}) \mathrm{PbBr}_{4}{ }^{25}$ & $" 3 \times 3 "(110)$ & 17.4 & 17.4 \\
$(\mathrm{BA})_{2} \mathrm{PbI}_{4}{ }^{66}$ & $(100)$ & 3.5 & 4.9 \\
\hline
\end{tabular}


Table 3. Room Temperature Data of the Optical Bandgaps, the PL Emission Center, the Energy Difference between FE and STE, the Average PL Lifetime, the Full Width at Half-Maximum (FWHM), the Commission International de I'Eclairage (CIE) Coordinates (x,y), the Correlated Color Temperature (CCT) and the Color Rendering Index (CRI) of the Compounds Reported Here

\begin{tabular}{lccccccccc}
\hline Compound & Bandgap (eV) & $\begin{array}{c}\text { PL emission } \\
\text { center (eV) }\end{array}$ & $\mathrm{E}_{\mathrm{FE}}-\mathrm{E}_{\mathrm{STE}}(\mathrm{eV})$ & $\tau_{\text {avg }}(\mathrm{ns})$ & $\begin{array}{c}\mathrm{FWHM} \\
(\mathrm{meV})\end{array}$ & $\mathrm{x}$ & $\mathrm{y}$ & $\mathrm{CCT}$ & $\mathrm{CRI}$ \\
\hline$(3 \mathrm{APr}) \mathrm{PbI}_{4}$ & 2.56 & 2.29 & 0.53 & 0.53 & 670 & 0.40 & 0.47 & 4122 & 77 \\
$(3 \mathrm{APr}) \mathrm{PbBr}_{4}$ & 3.29 & 2.10 & 0.81 & 1.72 & 743 & 0.43 & 0.45 & 3456 & 83 \\
$(3 \mathrm{APr}) \mathrm{PbCl}_{4}$ & 3.85 & 2.01 & 1.05 & 1.01 & 702 & 0.47 & 0.45 & 2835 & 85 \\
\hline
\end{tabular}



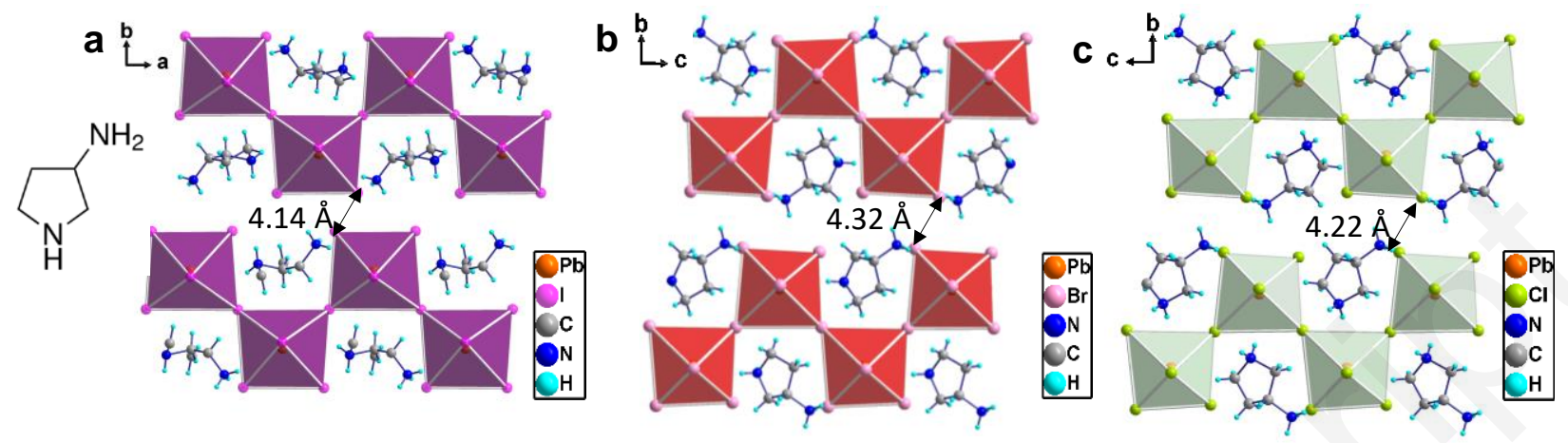

Figure 1. Crystal structures for (3APr)PbX 4 (X = I, Br, Cl) at $298 \mathrm{~K}$. (a) (3APr)PbI 4 (b) $(3 \mathrm{APr}) \mathrm{PbBr}_{4}$ and (c) (3APr) $\mathrm{PbCl}_{4}$.
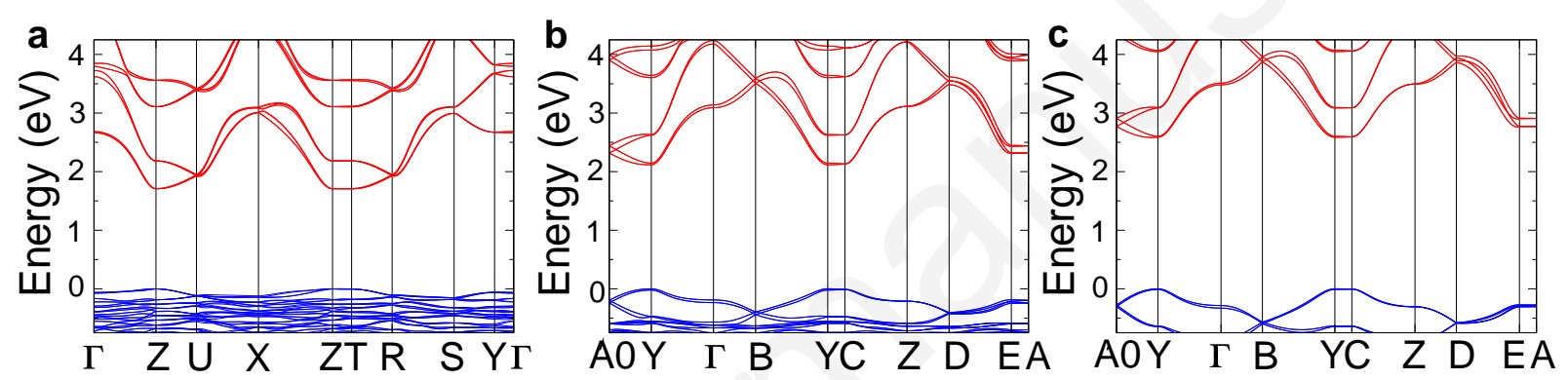

Figure 2. DFT calculations of band structures for ( $3 \mathrm{APr}) \mathrm{PbX}_{4}(\mathrm{X}=\mathrm{I}, \mathrm{Br}, \mathrm{Cl})$. (a) $(3 \mathrm{APr}) \mathrm{PbI}_{4}$ (b) (3APr) $\mathrm{PbBr}_{4}$ and (c) (3APr) $\mathrm{PbCl}_{4}$. 
a

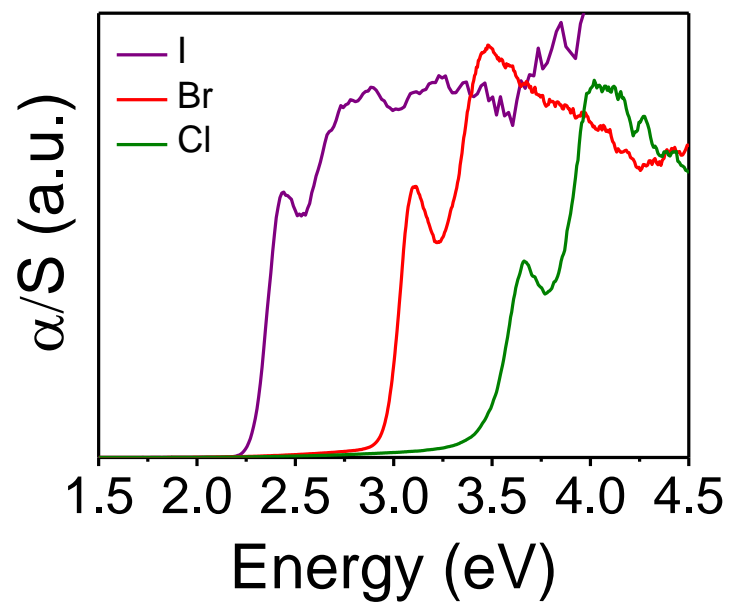

b

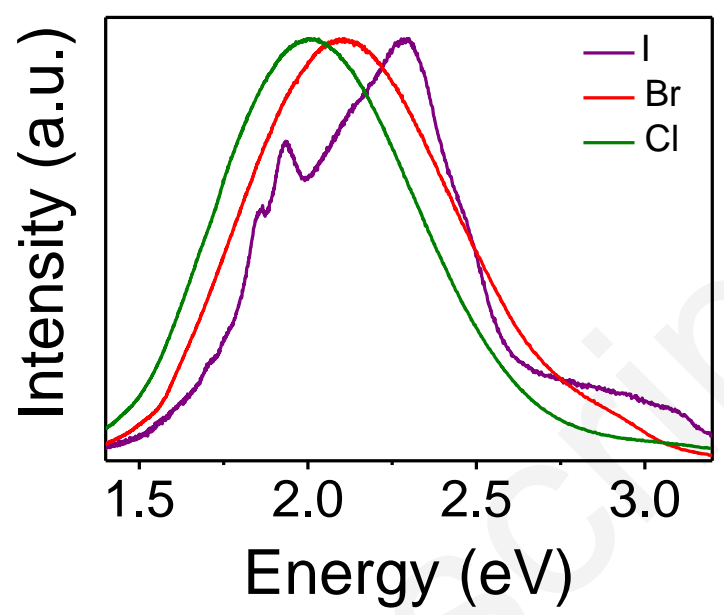

Figure 3. (a) optical absorption spectra and (b) steady-state PL at room temperature for $(3 \mathrm{APr}) \mathrm{PbX} 4(\mathrm{X}=\mathrm{I}, \mathrm{Br}, \mathrm{Cl})$.
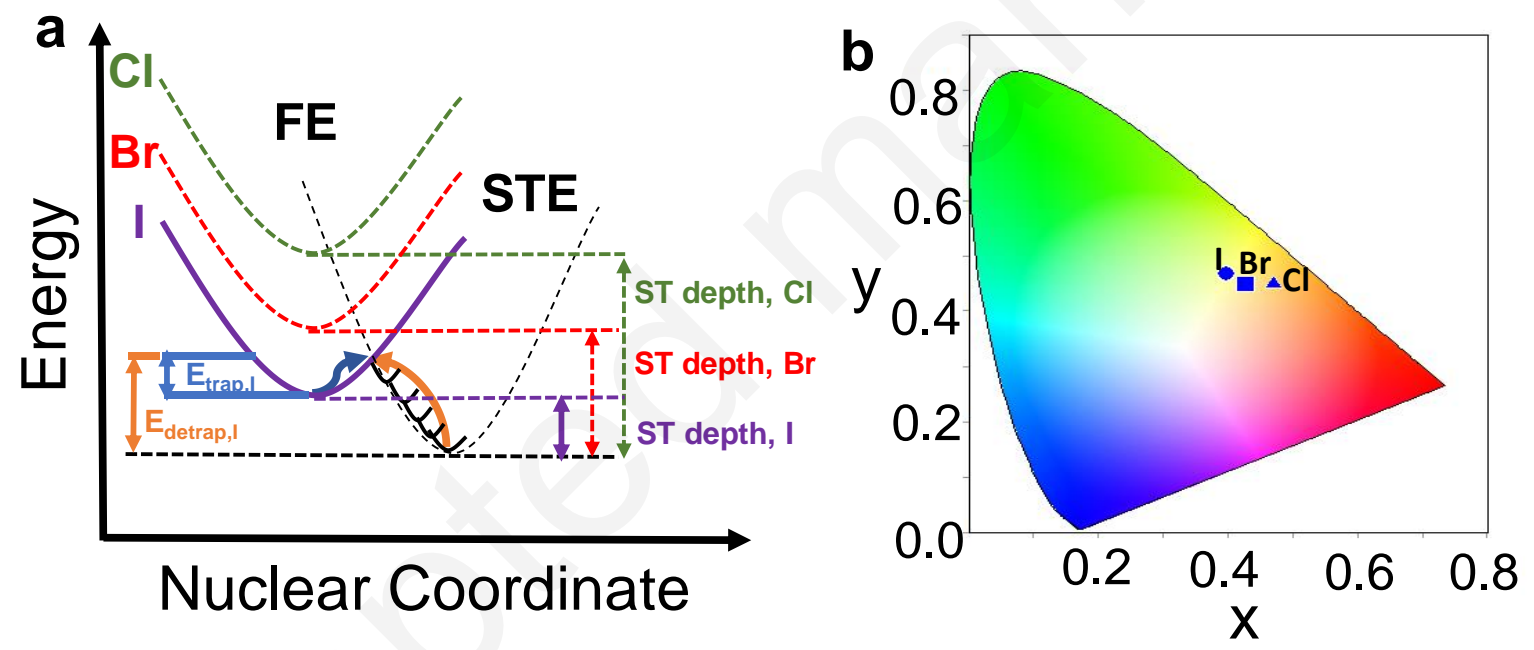

Figure 4. (a) Schematic comparison of self-trapping mechanism for ( $3 \mathrm{APr}) \mathrm{PbX} 4(\mathrm{X}=\mathrm{I}, \mathrm{Br}, \mathrm{Cl})$. Self-trapping (blue arrow) and detrapping (orange arrow) are shown only for the iodide perovskite as an example ( $\mathrm{FE}=$ free exciton, $\mathrm{STE}=$ self-trapped exciton, $\mathrm{E}_{\text {trap }}=$ energy for self-trapping, $E_{\text {detrap }}=$ energy for detrapping, self-trapping (ST) depth = energy difference between FE and STE). (b) $\mathrm{CIE}$ color coordinates of $(3 \mathrm{APr}) \mathrm{PbX}_{4}(\mathrm{X}=\mathrm{I}, \mathrm{Br}, \mathrm{Cl})$ in 1931 color space chromaticity diagram. 

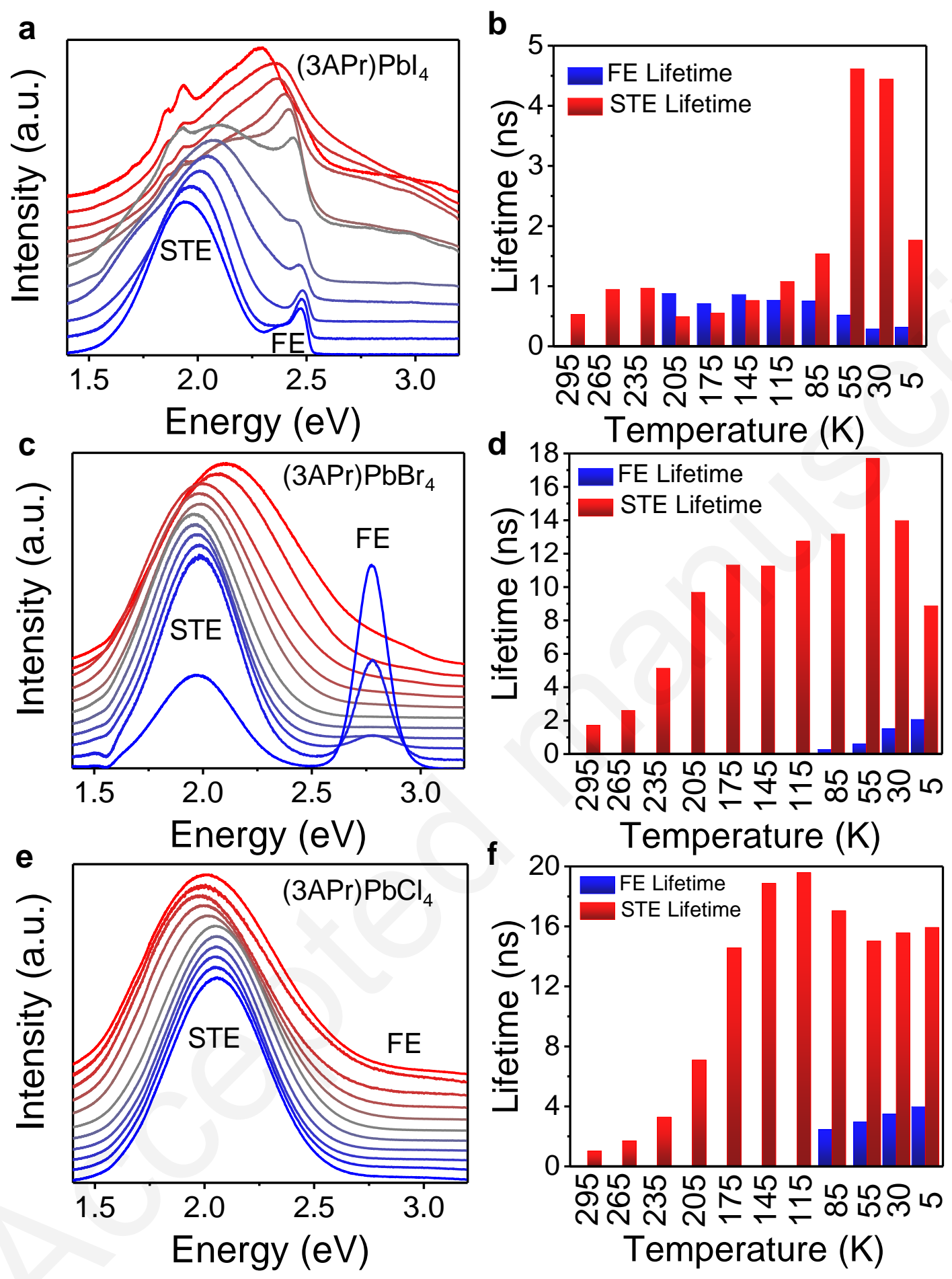

Figure 5. Temperature-dependent (5-295 K) steady-state PL spectra and average PL lifetimes for the free excitons (FE) and self-trapped excitons (STE) of (a)(b) (3APr)PbI ${ }_{4},(c)(d)(3 \mathrm{APr}) \mathrm{PbBr}_{4}$ and (e)(f) (3APr) $\mathrm{PbCl}_{4}$. Temperatures change from high to low for the spectra from top to bottom, temperature interval as indicated by the $\mathrm{x}$-axis on the right. 


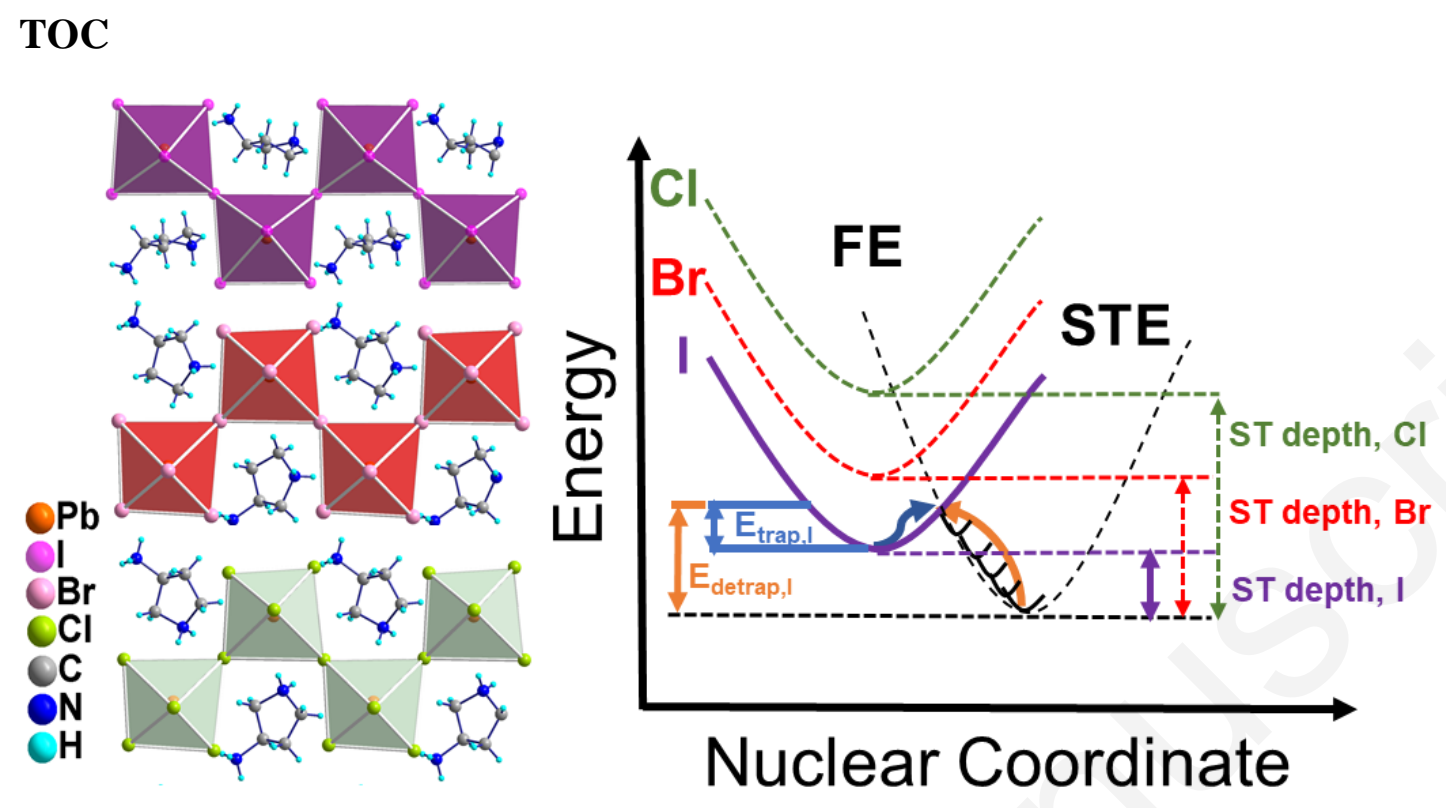

